\title{
First Record and Re-description of Tenuipalpus eriphyoides Baker (Acari: Prostigmata: Tenuipalpidae) in Egypt
}

\author{
Azza A. Mohamed"; A. M. Mohamed ${ }^{* * *}$ and I. R. M. El-Zoghby ${ }^{* * * *}$ \\ *Plant Protection Research Institute, ARC, Dokki, Giza, Egypt \\ ***The Central Laboratory for Date Palm Researches and Development, ARC, Dokki, Giza, Egypt. \\ ${ }^{* *}$ Plant Pro. Dept. Faculty of Agric. Aswan Univ., Aswan, Egypt.
}

\begin{abstract}
The tenuipalpid mite, Tenuipalpus eriophyoides is recorded for the first time in Egypt. Moreover, re-description for males and females collected on leaves of palm trees is provided.
\end{abstract}

Key Words: Tenuipalpus eriphyoides, morphology.

\section{INTRODUCTION}

Family Tenuipalpidae is worldwide in distribution and includes several economically important pest species (Mesa et al., 2009). Although the members of the genus Tenuipalpus Donnadieu is the largest numbers in this family (Mesa et al., 2009; Khanjani et al., 2012) only two species belonging to genus Tenuipalpus have been recorded in Egypt (Zaher, 1984). Despite the high diversity of mites in Egyptian agro-ecosystems, the family Tenuipalpidae has been poorly studied (Halawa and Fawzy, 2014). Several papers on mites of this family were published by Sayed (1942, 1946, 1950), Attiah (1956), and Zaher (1984) where the following two species Tenuipalpus granati Sayed on grape-vine and T. punicae P. \& B. on pomegranate were reported. AlGboory (1987) studied the false spider mites and referred to Tenuipalpus eriphyoides as a pest of date palm trees of central Iraq. Al-Gboory \& Al-Houty, 1990 collected this species from Baghdad and Kuwait then re-descriped and illustrated it. From 1984 up to date no new records of Tenuipalpus species in Egypt have been obtained. This may be likely due to the few interest in this group of mites. So, this paper presents the first record and re-description of the flat mite, Tenuipalpus eriophyoides from Egypt.

\section{MATERIALS AND METHODS}

The flat mite Tenuipalpus eriophyoides was collected from leaves of palm trees in Sohag governorate through the survey programs of Plant Protection Research Institute on date palm trees during the period from 2010 to 2011. Samples were collected bi-weekly and transported in the same day to Shandaweel Agricultural Research Station, Agricultural Research Center (ARC), Sohag. Mites were collected using a fine hair brush under dissection stereo-microscope, then preserved in 70\% ethanol. Selected mites were cleared in Nesbitt solution for 10-12 minutes. Subsequently, mites were mounted on micro-slides in Hoyer's medium, and later dried at $40{ }^{\circ} \mathrm{C}$ for one week (Zhang, 2003). The terminology used in the key followed Linquist (1985) and Mesa et al. (2009). The measurements were given in micrometers $(\mu \mathrm{m})$. The type materials were deposited in the mite collection of the Agriculture Research Center, Plant Protection Research Institute, Cotton and Crops Acarology Department, The mite was identified and described according to Meyer, (1987).

\section{RESULTS AND DISCUSSION}

Tenuipalpidae Berlese, 1913

Tenuipalpus Donnadieu, 1876

Tenuipalpus eriophyoides Baker, 1948: 59; Pritchard \& Baker, 1958: 246.

Colopalpus eriophyoides Baker \& Tuttle, 1972: 35; Al-Gboory \& Al-Houty, 1990: 36.

Tenuipalpus labidosus Siddiqui \& Chaudhri, 1972: 331; Chaudhri et al. (1974). Baker \& Pritchard (1953b); Khosrowshahi \& Arbabi (1997), Meyer (1979), Mitrofanov \& Strunkova (1979), Chaudhri (1972c)

\section{Description:}

Female (Fig.1): Colour dark red. Gnathosoma without a pair of ventral gnathosomal setae, rostrum reaching above the first quarter of femur I. Palpus with three segments, the first (= basal) segment very small, the second segment the longest and bearing dorsally a pectinate seta and the third segment with a single sensory seta.

Dorsum: The rostral shield acutely and deeply bifurcate and not covering the rostrum. Propodosoma with a few transverse striations medially and posteriorly, remaining propodosomal area with a few irregular longitudinal and transverse striations. Eyes two pairs, one pair on each side. Dorsal propodosoma 


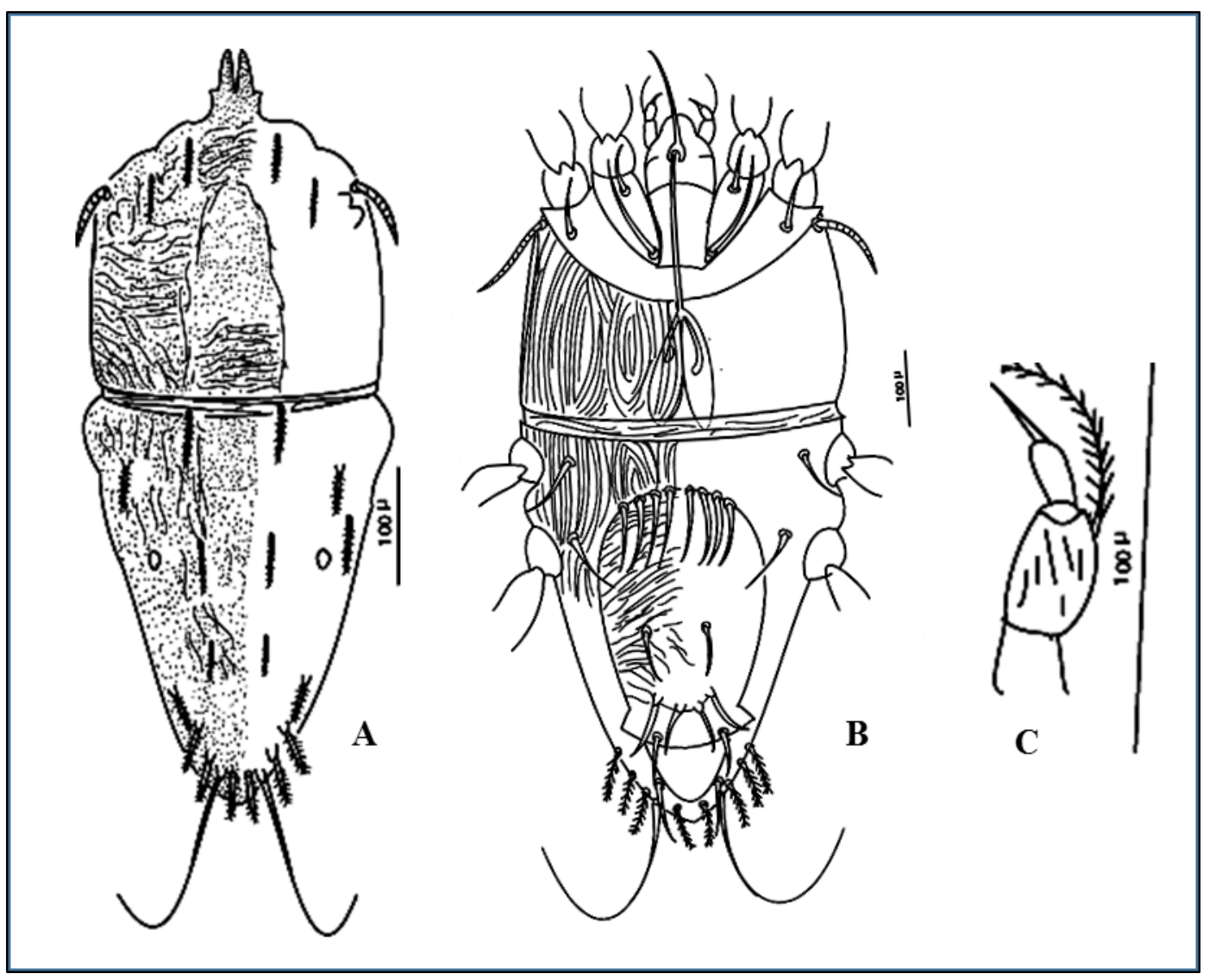

Fig. (1): Tenuipalpus eriphyoides (female): A. Dorsal idiosoma; B. Ventral idiosoma; C. Palpus.

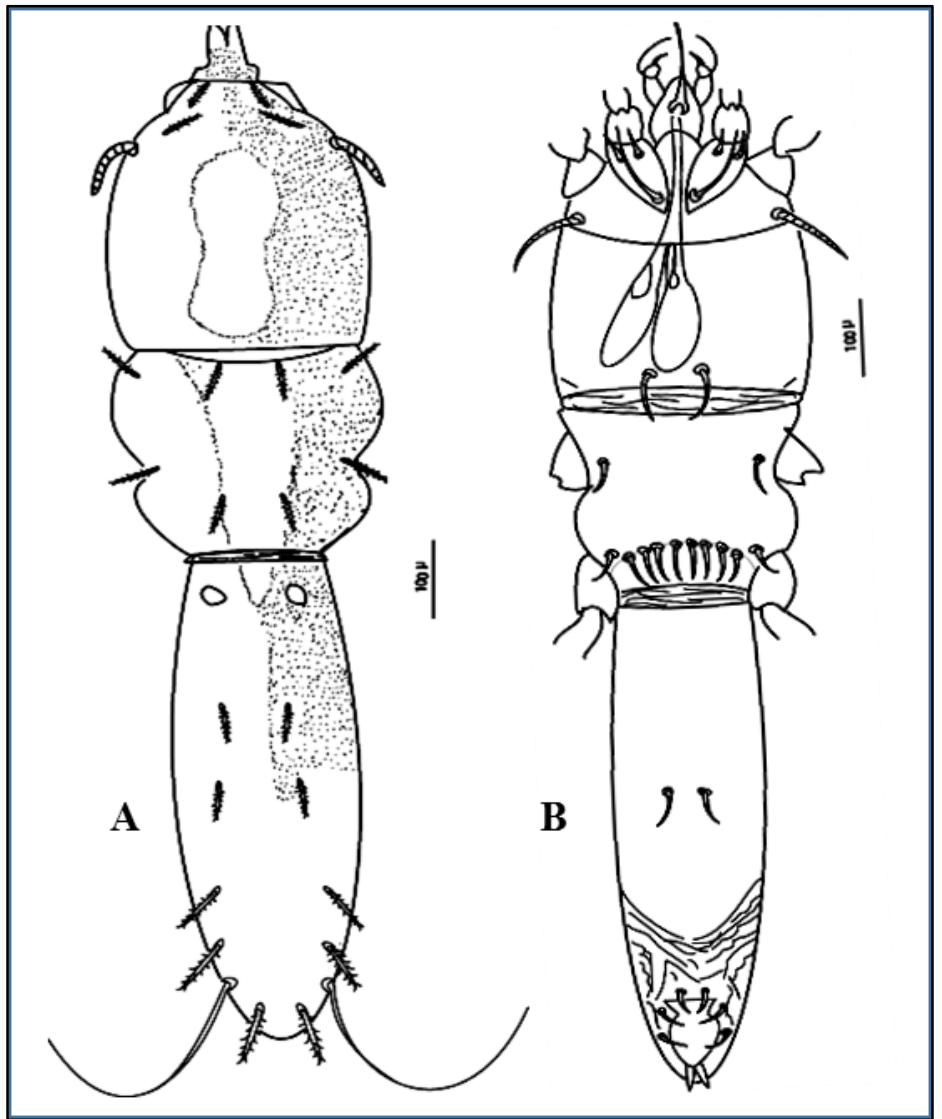

Fig. (2): Tenuipalpus eriphyoides (male): A. Dorsal idiosoma; B. Ventral idiosoma. 
with three pairs of serrate, narrowly lanceolate setae. Humeral suture well defined medially and laterally Hysterosoma with few longitudinal striations laterally infront of areas of legs III and IV. The dorsomedial area of hysterosoma without striations, with one pair of pores, one on each side. Dorsocentral hysterosoma with three pairs of serrate, narrowly lanceolate setae and with one pair of humeral serrate setae. Dorsolateral hysterosoma with six pairs of setae; I, II, III, IV and VI serrate and (V) flagelliform. Dorsum has pitted appearance.

Venter: Venter of propodosoma and metapodosoma with regular, longitudinal striations up to the bases of posterior medioventral metapodosomal setae. Medioventral propodosoma with one pair of whiplike, simple setae. Anterior medioventral metapodosoma with one pair of simple setae. Posterior medioventral metapodosoma with four pairs of simple setae, having the same length and reaching bases of the genital setae. The genito-ventral (= ventrigenital) shield with transverse striations; ventral with one pair of simple setae. Genital with two pairs of simple setae. Anal shield distinct with two pairs of simple setae.

Legs: With four pairs of wrinkled and pitted segments.

Legs I - IV chaetotaxy as follows:

\begin{tabular}{lcccc}
\hline Podomers & L1 & L2 & L3 & L4 \\
\hline Coxae & 2 & 2 & 1 & 1 \\
\hline Trochanters & 1 & 1 & 1 & 1 \\
\hline Femora & 4 & 4 & 2 & 1 \\
\hline Genua & 2 & 2 & 1 & 1 \\
\hline Tibiae & 5 & 5 & 3 & 3 \\
\hline
\end{tabular}

Tarsi I and II each with a single solenidion.

Male (Fig.2): The male is very distinctive in having an elongate body, especially the opisthosoma. Gnathosoma as in the female.

Dorsum: Rostral shield deeply cleft and covers the rostrum. Propodosoma pitted without striations. The posterior part of propodosoma smooth medially. Hysterosoma pitted except smooth area between the first dorsocentral hysterosomal setae and the end of opisthosoma. Hysterosoma divided into two parts with transverse striae. One pair of pores present. Dorsal body setae similar to those of the female.

Venter: With few transverse striations mostly between the metapodosoma and opisthosoma. Medioventral propodosomals, anterior medioventral metapodosomals and posterior medioventral metapodosomals similar to that in the female. Ventral shield, not well distinct, with one pair ventral setae. Genitoanal shield with three pairs of genitoanal, simple setae. End of the body with one pair of terminal genital stylets.

Legs: Leg chaetotaxy resembles that of female, except that tarsi I-IV each with two solenidia.

Type specimens: Six females and two males collected from Sohag governorate, deposited at the Mite Collection of Plant Protection Research Institute, Agricultural Research Center, Cotton and Crops Acarology Department, Dokki, Cairo, Egypt.

Remarks: This species is found with a high host specify, living on both sides of leaves of palm trees.

\section{ACKNOWLEDGEMENTS}

Authors express their deep gratitude to Dr. A. M. Halawa (Fruit Acarology Department, Plant Protection Research Institute, Agricultural Research Centre, Dokki, Giza, Egypt) for his help, support and cooperation. Deepest thanks also extended to Dr. R.I.A. Abo-Shnaf (Vegetable and Aromatic Plant Mites Department, Plant Protection Research Institute, Agricultural Research Centre, Dokki, Giza, Egypt) for assuring identification of mite materials.

\section{REFERENCES}

Al-Gboory, I. 1987. Taxonomic studies of false spider mites (Acari: Tenuipalpidae) in Central Iraq. Ph. D. Thesis, University of Bonn, West Germany 205 pp.

Al-Gboory, I. and Al-Houty, W. 1990. Redescription of Colopalpus eriphyoides (Baker) (Acari: Tenuipalpidae). Bull. Iraq Nat. Hist. Mus., 8 (3): 35 - 43.

Attiah, H. 1956. The genus Brevipalpus in Egypt. Bull. Soc. Ent. Egypte, 40: 433-477.

Baker, E. W. 1948. A new Tetranychid mite which further indicates a phylogenetic relationship between the Tenuipalpidae and the Eriophyidae (Acarina). Proc. Ent. Soc. Wash., 50 (3): 59-60.

Baker, E.W. and Pritchard, A. E. 1953 . The family categories of Tetranychoid mites, with a review of the new families Linotetranidae and Tuckerellidae. Ann. Ent. Soc. America, 46(2) :243-58.

Baker, E.W. and Tuttle, D. H. 1972. New species and further notes on the Tetranychoidea mostly from the 'Southwestern United States (Acarina: Tetranychidae and Tenuipalpidae). Smith. Cont. Zool., 116: 1-37.

Chaudhri, W.M. 1972. Description of five new 
species of Tenuipalpus (Acarina: Tenuipalpidae) from Pakistan. Sind University Research Journal, 6 (1): 17-29.

Chaudhri, W.M.; Akbar, S. and Rasool, A. 1974. Taxonomic studies of the mites belonging to the families Tenuipalpidae, Tetranychidae, Tuckerellidae, Caligonellidae, Stigmaeidae and Phytoseiidae. University of Agriculture, Lyallpur, Pakistan. Project No. A17-Ent-26: 1-250.

Halawa, A.M. and Fawzy, M.M. 2014. A new species of Brevipalpus Donnadieu (Acari: Tenuipalpidae) and key to the Egyptian species. Zootaxa, 3755 (1): 87-95.

Khanjani, M.; Khanjani, M. and Seeman, O. D. 2012. The false spider mites of the genera Aegyptobia Sayed and Phytoptipalpus Trägårdh (Acari: Tenuipalpidae) from Iran. Zootaxa, 3295: 30-58.

Khosrowshahi, M. and Arbabi, M. 1997. The Tenuipalpidae (Acari) of Iran with introduction of new species for the world fauna and Iran. Ministry of Agriculture, Agriculture Research, Education and Extension Organization Plant Pests and Diseases Research Institute, Tehran, 1-19.

Lindquist, E.E. 1985. Anatomy, phylogeny and systematics. In Helle, W. \& Sabelis, M.W. (Eds.), Spider mites, the biology, natural enemies and control. Elsevier, Amsterdam, 1A, pp. 272- 418.

Mesa, N.C.; Ochoa, R.; Welbourn, W.; Calvin Evans, G.A. and Moraes, G.J.de.2009. A catalog of the Tenuipalpidae (Acari) of the world with a key to the genera. Zootaxa, 2098: 1-185.

Meyer, M.K.P. 1979. The Tenuipalpidae (Acari) of Africa with keys to the world fauna. Entomology Memoir, Department of Agriculture Republic South Africa, Pretoria, 50, 1-133.
Meyer, M. K. P. 1987. African Tetranychidae ( Acari : Prostigmata) with reference to the world genera. Entomology Mem. Dep. Agric. Wat. Supply Repub. S. Afr., (69): 175 pp.

Mitrofanov, V.I. and Strunkova, Z.I. 1979. A key to false spider mites. Operdelitl'Kleshcheiploskotelok, USSR, 148: 1-148.

Pritchard, A.E. and Baker, E.W. 1958. The false spider mites Acarina: (Tenuipalpidae). University of California Publication in Entomology, 14 (3): 175-274.

Sayed, M.T. 1942. Contribution to the knowledge of Acarina of Egypt. II-The genus Tenuipalpus Donnadieu Tetranychidae). Bull. Soc. Fouad Ier. Entomol., 26: 93-113.

Sayed, M.T. 1946. Description of Tenuipalpus granati nov. spec. and Brevipalpus pyri nov. spec. Bull. Soc. Fouad Ier. Entomol., 30, 99-104.

Sayed, M.T. 1950. On the taxonomy of tetranychidae and allied genera. A new family and two new subfamilies in Acarina. Proc. Eight Int. Cong. Entomol., : 1012-1017.

Siddiqui, E.M. and Chaudhri, W.M. 1972. Three new species of mites of the genus Tenuipalpus from Pakistan (Tenuipalpidae). Pakistan Journal of Scientific Research, 24(3/4): 328-332.

Zaher, M. A. 1984. Survey and ecological studies on phytophagous, predaceous and soil mites in Egypt. 1. Phytophagous mites in Egypt (Nile valley and delta). PL 480 Programme U. S. A., Project No. EG-ARS-30, Grant No. FG-EG-139, 1-226 pp.

Zhang, Z. Q. 2003. Mites of Greenhouses: Identification, Biology and Control. Centre of Agriculture and Biosciences International Publishing, Wallingford, United Kingdom, xii 244 pp. 